\title{
Entre o Borralho e o Divino: a emergência musical da "periferia"1
}

Felipe da Costa Trotta

Resumo: A periferia está em evidência em diversos discursos midiáticos e sociais no Brasil e no mundo. Este texto busca discutir o papel da música no processamento dessa emergência da periferia a partir da análise de alguns exemplos das trilhas sonoras das novelas Cheias de charme (Globo, 2012, 19h00) e Avenida Brasil (Globo, 2012, 21 h00). Argumenta-se que, apesar de suas diversificadas sonoridades e conteúdos, a circulação de músicas em larga escala em torno da ideia de periferia estabelece uma continuidade entre esse vocábulo e uma (re)posição política dos setores "populares". A "periferia" é um termo que aparece positivado no repertório musical compartilhado e a partir dessa positivação articula tensões e enfrentamentos sociais variados. As músicas são formas de pensamento e ação no mundo que negociam valores e ideias. Nesse caso, as músicas periféricas, de massa, produzem modos de elaborar assimetrias de poder e pertencimentos sociais hierarquizados.

Palavras-chave: música popular, periferia, telenovela.

Abstract: Between "Borralho" and "Divino": the musical emergency of periphery - The periphery is in evidence in the media not only in Brazil but also worldwide. This paper discusses the role of music in this emergency of the periphery from the analysis of some examples of the soundtracks of telenovelas Cheias de charme (Globo, 2012, 19h) and Avenida Brasil (Globo, 2012, 21h). Despite their diverse sonority, this repertoire activates a common feeling of "popular", related to the ideia of periphery. Periphery is a term that appears positively in shared musical repertoire, which evokes social tensions and confrontations. The music is a form of thought and action in the world, sharing values and ideas. In this case, peripheral mass musics produce ways of negotiating power asymmetries and hierarchical social affiliations.

Keywords: popular music, periphery, telenovela

1 "A presente pesquisa conta com o apoio do CNPq (bolsa de produtividade) e da Faperj (Jovem Cientista de Nosso Estado)." 


\section{Introdução}

De forma recorrente, deparamos-nos com discursos que abordam a emergência cultural da periferia. São matérias de jornais e revistas, depoimentos, análises políticas e econômicas e uma ampla variedade de produtos culturais que circulam a partir da enunciação de um "olhar" e uma "escuta" periférica. ${ }^{2}$ Tanto em âmbito local, nacional ou internacional, vivemos um momento cultural no qual os países, regiões e bairros periféricos têm despertado a atenção dos setores dominantes da economia, política e cultura. No Brasil, o interesse na periferia tem sido vinculado à ampliação do consumo e da participação da chamada "classe C" na economia nacional. Estabelece-se uma conexão entre o aumento do contingente populacional desse segmento e a ampliação da circulação de estéticas associadas a gostos específicos da "nova classe média" (NEGRI, 2010).

A periferia é um vocábulo que integra ao mesmo tempo um local, transformado em símbolo metonímico, as pessoas, incluídas nos estratos de menor poder aquisitivo da população, e o estilo de vida e de consumo dessas pessoas, que habitam esse local. Emerge da e na periferia uma gama de produtos culturais associados a um conjunto de ideias e processamentos sobre o popular, que tematiza e elabora significados sobre esse local físico e simbólico. Quero propor aqui que um dos principais produtos desse processamento - senão o principal - é a música.

No jogo conflituoso de hierarquias entre o central e o periférico, entre o "dominante" e o "subalterno", as músicas periféricas de massa forçam vazamentos entre posições sociais hierarquizadas, mobilizando sonoramente preconceitos, (in)tolerâncias e diversão. São músicas de ampla circulação, com estrutura comercial eficiente e público numeroso, que atravessam fronteiras geográficas e sociais, criando territórios de gostos compartilhados em larga escala.

Neste texto, irei discutir um pouco esse processo a partir das trilhas sonoras de duas telenovelas da Rede Globo de grande sucesso no ano de 2012: Cheias de charme (de Filipe Miguez e Izabel de Oliveira), exibida entre abril e setembro no horário das 19h00, e a elogiadíssima Avenida Brasil (de João Emanuel Carneiro), exibida simultaneamente entre março e outubro no horário nobre das $21 \mathrm{~h} 00$. Não por acaso, ambas as novelas tiveram locações principais em bairros populares (periféricos) e conquistaram audiência expressiva em seus respectivos horários.

2 Para confirmarmos esse interesse, basta uma pequena vasculhada em títulos de matérias de jornais e revistas como "Classe C vai às compras e empurra mercado de TV por assinatura no Brasil" (UOL, 22/01/2013), "Novas vozes da periferia" (O Globo, 03/11/2012), "Atrás da nova classe C, publicidade muda estratégias e vai à periferia" (G1, 13/01/2013), "Editorial: cultura na periferia" (Folha SP, 03/11/2012), "40,3 milhões entram na classe C em sete anos" (Época Negócios, 13/01/2013). Exposições como "Design de periferia" (SP, janeiro de 2013) ou "Estética da periferia" (RJ, 2007), e dezenas de produtos audiovisuais (filmes, programas de TV, vídeos) compõem uma rede de produções sobre a emergência da periferia, que tem despertado interesse em vários setores da sociedade. 
É interessante notar ainda que as duas produções despertaram o interesse de pesquisadores de diversas áreas, que durante o ano publicaram reflexões sobre as tramas. Essas reflexões têm como marco inicial o aumento do consumo da "classe C" (TARAPANOFF e FERNANDES, 2012; IORIO, 2012; RAHDE et al., 2012; FRANÇA eVAZ, 2012), a partir do qual discutem fundamentalmente a transmidiação (CASTRO 2012; SIFUENTES et. al., 2012; LIMA e MOREIRA, 2012) e as tensões de classe (BARROS, 2012; MAURO e TRINDADE, 2012; KANYAT 2012).

Contudo, mais do que constatar a emergência dessa visibilidade e audibilidade da periferia nas tramas televisivas e o saudável interesse acadêmico pelo tema, interessa-me apontar para o repertório musical por elas acionado. A música é uma "forma de pensamento e ação no mundo" (BLACKING, 1995, p. 235), sendo utilizada para construir identificações individuais e estabelecer conexões e compartilhamentos éticos e estéticos. Mais do que a representação da periferia ou do popular, as músicas negociam modos de pertencimento, de valorização e de circulação de discursos sobre esse popular. Pensar sobre o papel da música nesse processo pode ser um caminho alternativo entre a celebração hiperbólica das práticas periféricas e a condenação preconceituosa de tudo o que vem dos "pobres". Ou entre o discurso acusatório das desigualdades sociais e o tom festivo que comemora a criatividade da "cultura periférica".

\section{Casa Grande e Borralho: as "Empreguetes"}

Cheias de charme tinha como protagonistas três empregadas domésticas, que, em determinado momento da trama, formaram um grupo musical e se tornaram estrelas do showbizz. O sucesso do trio Empreguetes, formado por Maria da Penha (Taís Araújo), Maria Aparecida (Isabelle Drummond) e Maria do Rosário (Leandra Leal), desperta, na trama, uma inveja patológica na cantora de "eletroforró" Chayene (Claudia Abreu), que passa a arquitetar planos estapafúrdios para boicotar a carreira de Penha, Cida e Rosário.

Piauiense de Sobradinho, Chayene é um personagem cômico, caracterizada com roupas espalhafatosas, exagero em adereços, plumas, brilhos e gestos, além de seu sotaque nordestino estereotipado e de uma certa ingenuidade infantil, mesmo na maquinação de suas intrigas. ${ }^{3}$ Completa a estrutura dramática da novela o cantor romântico Fabián (Ricardo Tozzi), alvo de desejos sexuais de Chayene e ídolo da "empreguete" Rosário, por quem acaba se apaixonando. A interpretação musical de Fabián é caricatamente sensual,

3 O personagem de Chayene é bastante interessante. Nordestina, Chayene encarna todos os estereótipos desqualificantes que cercam o imaginário nacional sobre o Nordeste e sua excentricidade de artista é atravessada pelo preconceito contra sua origem geográfica, intensificada por seus trejeitos exagerados e sua predileção por brilhos e cores. O próprio gênero musical "eletroforró" é uma invenção da novela e faz referência ao forró eletrônico de sucesso absoluto no Nordeste, que apresenta uma versão pop e jovem para o tradicional gênero nordestino, mas é continuamente desqualificado pela crítica musical. Em torno de Chayene, configura-se um jogo complexo de preconceitos e estigmas relacionados à posição social e origem geográfica: o popular e o periférico. 
o que desperta o delírio de suas fãs, as "fabianáticas". Seu repertório inclui clássicos do cancioneiro romântico, como a canção Impossível acreditar que perdi você (Mário Greyck / Cobel, 1971) ${ }^{4}$ e Cheia de charme (Guilherme Arantes, 1985), inspiração do nome da novela. Com essa rede de personagens cantores, Cheias de charme foi uma novela musical, que contou com dezenas de participações de artistas "reais" do mercado musical, que formaram duetos com as Empreguetes, Fabián ou Chayene. ${ }^{5}$

Os conflitos entre patroas e empregadas formaram o pano de fundo da trama, materializada na oposição entre o condomínio de luxo "Casa Grande" e a favela do "Borralho". Sobre um esquema dicotômico bastante rígido e estereotipado, a trama desenvolve-se em torno da ideia da mobilidade social através do mérito (RONSINI, 2012).

Rosário e Penha trabalharam em momentos distintos como empregadas de Chayene, que se revelou uma patroa insensível, autoritária e exploradora. O caso foi levado à Justiça e abriu espaço, na novela, para oportunos debates sobre os direitos das empregadas, muitas vezes de forma cômica, mas eventualmente tratado com mais seriedade. Ao analisar a representação do trabalho doméstico na televisão, Carla Barros observa a posição privilegiada das empregadas como "intérpretes" e tradutoras de regras, gostos, estéticas e comportamentos distintos (BARROS, 2012, p. 76). Em Cheias de charme, essa tradução tensiva assume uma forma musical, realizada performaticamente através da ironia. A canção Vida de empreguete (Quito Ribeiro) é detonadora de uma reviravolta na trama ao ser veiculada com sucesso na internet e detonar a formação do trio.

Todo dia acordo cedo, moro longe do emprego

Quando volto do serviço, quero meu sofá

Tá sempre cheia a condução, eu passo pano, esfrego o chão

A outra vê defeito até onde não há

Queria ver madame aqui no meu lugar

Eu ia rir de me acabar (tirando a mesa do jantar)

Levo vida de empreguete, eu pego às sete

Fim de semana salto alto e ver o que vai dar

Um dia compro apartamento viro socialite

Toda boa vou com meu "ficante" viajar

O clipe é produzido por Kleiton (Fábio Neppo), amigo de Penha e dono da lan house da favela do Borralho, que se torna posteriormente produtor musical das Empreguetes. A sonoridade pop eletrônica da canção e a inspiração funkeira da primeira parte da música moldam uma ambiência que estabelece um lugar de fala (ou de canto) para as Empreguetes. Trata-se de um espaço físico e simbólico reconhecido como periférico -

4 Essa canção foi lançada, em 1971, pelo Trio Esperança e no ano seguinte pela cantora Perla. Em 1996, foi gravada pelo cantor Fabio Jr., em quem Fabián é fortemente inspirado.

5 Michel Teló, João Neto e Frederico, Zezé de Camargo e Luciano, Ivete Sangalo e Gaby Amarantos foram alguns desses artistas, todos com músicas incluídas na trilha sonora oficial da novela. No final de 2012, a Som Livre lançou um DVD com 17 cenas de performances musicais exibidas durante a trama. 
a favela, o transporte público, a jornada de trabalho, o trabalho braçal -, jovem, cosmopolita, festivo. Lan houses, sons eletrônicos e o canto falado do rap são significantes sonoros desse pertencimento, que fala sobre uma periferia conectada, integrada à sociedade e crítica sobre as exclusões e submissões da hierarquia das classes.

A risível inversão da "madame" no lugar da empregada insere-se na lógica binária da mobilidade, matizando o sonho utópico de uma dominação do dominado. Outro sucesso das Empreguetes, Marias brasileiras (Carlos Colla / Michael Sullivan), executada dezenas de vezes durante a trama, apresenta o mesmo programa retórico.

Marias brasileiras, de tudo sou capaz

Marias verdadeiras,

Tudo o que você fizer eu faço mais

Maria sem-vergonha, Marias sensuais

Maria vai com as outras

Quero ver você fazer o que ela faz

A narrativa hiperbólica das capacidades das "marias" manifesta uma crença na força das pessoas comuns, de mulheres trabalhadoras, poderosas e populares. Os nomes das personagens se associam ainda a igrejas e festas religiosas de forte significação popular: Penha, Aparecida e Nossa Senhora do Rosário. Trata-se de um popular festivo e comum, que reivindica valorização política e estética, reconhecimento e respeito. E que através da música - e do mérito - consegue sua mobilidade social.

A consciência do processo é emblematicamente apresentada pela personagem Rosário, que, ao discursar na entrega de um importante prêmio de música recebido pelas Empreguetes, na trama dedica o troféu à força da periferia.

Eu acho que a gente tem que dedicar esse prêmio para todos os artistas de periferia que cansaram de esperar uma oportunidade e resolveram mostrar o seu trabalho. Se antes a cultura não chegava na periferia, agora é a cultura da periferia que chega no mundo todo através da internet. Pra esses artistas que a gente dedica esse prêmio. (personagem Rosário, capítulo 139, exibido em 24/9/2012)

Essa declaração extrapola os limites da novela e funciona como uma espécie de editorial. No discurso da personagem, o termo periferia é utilizado de modo político, funcionando como elemento agregador de um conjunto populacional, identificado com o universo popular. Brota nessa fala outro aspecto importante da circulação das músicas periféricas de massa, que é a tecnologia. Se em muitos momentos da história o acesso ao consumo tecnológico funcionou como uma barreira intransponível para os setores de menor poder aquisitivo, o barateamento digital recente tem possibilitado apropriações diversificadas da tecnologia, com acesso ampliado. A internet, assim como as telenovelas, 
são elementos culturais que atravessam classes e estão disponíveis a uma ampla maioria da população. ${ }^{6}$ Contudo, não podemos deixar de notar, no discurso de Rosário e na própria história da novela, certa "idealização da internet como portal mágico de pessoas comuns rumo ao estrelato" (CASTRO, 2012, p. 63).

Na trama, Vida de empreguete foi lançada na internet e fora dela, através do portal Globo, e teve, de fato, em ambas, um comportamento viral. Foi essa viralidade que permitiu a explosão do trio e sua bem sucedida carreira musical. De certo modo, o sucesso da canção sugere que a veiculação livre de músicas na internet funciona automaticamente como vitrine de exposição garantida, capaz de pavimentar o caminho de qualquer "artista de periferia" para o sucesso, o estrelato e a mobilidade social. Sabemos que não é bem assim na "vida real". Entretanto, o que nos interessa reter momentaneamente é a caracterização dramática de uma ambiência que articula uma determinada música (pop), um segmento populacional (o "povo"), um vocábulo geográfico com função metonímica (a "periferia") e um modo de circulação (a "internet").

\section{O Divino: futebol e pagode}

A representação do bairro popular do Divino, em Avenida Brasil, insere-se em uma tendência da teledramaturgia nacional de caracterização do bairro pobre e dos personagens populares não em suas tramas secundárias, mas como eixo central da ação dramática (RONSINI, 2012, p.14). Novelas como Senhora do Destino (Aguinaldo Silva, 2004), Duas Caras (Aguinaldo Silva, 2007), Cheias de charme e séries como Cidade dos homens (2002), Antônia (2006) e Subúrbia (2012) são exemplos de transformações na ficção seriada, que passa a retratar com mais frequência o "cotidiano das classes C, D e E no Brasil de maneira séria" (JUNQUEIRA, 2009, p. 161). Avenida Brasil, diferentemente de Cheias de charme, caracteriza-se pela forma escorregadia com que as tensões de classe são apresentadas, fugindo das dicotomias mais convencionais.

Na trama, a clássica oposição entre pobres e ricos se desloca para as assimetrias entre um bairro suburbano fictício e um lixão, sendo um caso raro de representação da pobreza extrema na ficção televisiva, ainda que revestida de uma atmosfera "mágica" (FRANÇA e VAZ, 2012). O "núcleo periférico, de menor importância para o desenvolvimento da trama desta novela, mora na zona sul do Rio de Janeiro, lugar nobre, [e] são pessoas da chamada classe alta (A e B) que formam um núcleo cômico" (RAHDE et. al, 2012, p. 332). Há, em Avenida Brasil, desde o título, uma intenção explícita de negociar o trânsito e a mobilidade entre geografias e classes.

O nome é sugestivo, e sobretudo para os telespectadores não-cariocas, ele se abre a várias possibilidades semânticas: é a via onde estamos todos nós, brasileiros -

6 É evidente que não podemos ignorar as diferenças ainda gritantes na qualidade e na regularidade do acesso entre as elites e os setores populares. Estou apenas querendo sublinhar a disponibilidade do uso, concretamente exercida, sobretudo pelos jovens. 
a avenida Brasil é o Brasil. Nesse sentido, a novela é a nossa cara. É também (e isto num cenário nacional e internacional) o Brasil como uma avenida, uma via aberta para o futuro, para novos rumos. Para os moradores da cidade, ou para quem conhece a geografia do Rio, é uma avenida de mão dupla, que tanto vai da zona sul para a zona norte, quanto vem da zona norte para a zona sul. Na realidade carioca, é o principal acesso rodoviário de trabalhadores que habitam no subúrbio e trabalham na zona sul do Rio, o que indica qual é a população que trafega preferencialmente por ela (indo e voltando). (FRANÇA eVAZ, 2012, p. 7).

Numa das saídas dessa longa avenida, encontramos o bairro do Divino, locação principal da novela. O Divino é um lugar humilde, mas próspero, onde se localiza a mansão de Tufão (Murilo Benício), ex-jogador de futebol do Flamengo que se transforma em homem de negócios. Integram os cenários recorrentes do bairro um salão de beleza, um bar, um shopping popular e a sede do Divino Futebol Clube (TARAPANOFF e FERNANDES, 2012, p. 11), onde joga Jorginho, o filho adotivo de Tufão.

A localização física e afetiva do bairro está moldada significativamente na articulação entre o futebol e a música. O ambiente do futebol - mais precisamente dos jogadores de futebol - estabelece um tipo de vinculação e de discurso sobre o popular. O futebol é uma atividade de lazer que, nas camadas de menor poder aquisitivo da população, assume a forma também de uma possibilidade de mobilidade social, obtenção de prestígio e dinheiro. Por essa razão, a profissão tem grande poder de sedução entre jovens do sexo masculino de classes baixas, apesar das chances relativamente pequenas de sucesso no mercado futebolístico (DAMO, 2005, pp.15-16). Essa sedução é reforçada pela ampla divulgação midiática da origem social pobre de jogadores de fama internacional, muitas vezes passando por bairros e clubes de futebol semelhantes ao Divino.

Nas narrativas sobre as trajetórias dos jogadores na mídia esportiva (e além dela), um certo estilo de vida popular é continuamente destacado chamando a atenção para a infância pobre e talento inato dos ídolos (HELAL, 2003, p. 20). Em alguns casos, a origem popular se torna um eixo explicativo para uma ética desviante, associada a uma moral específica da periferia. Ao discutir a cobertura da imprensa sobre a trajetória de Romário, por exemplo, Helal observa que sua eficácia nos gramados inverte características morais negativas que aparecem valorizadas em torno das ideias de "irreverência" e "malandragem" (ibid., p. 28).

Ao contrário de Romário, Tufão é caracterizado, na novela, como um "ex-jogador, rico e pacato", sem maiores ambições (FRANÇA e VAZ, 2012), cuja alegria se encontra fundamentalmente na família e nos raros momentos de lazer. O futebol é uma atividade que está no passado, que permitiu sua ascensão social e que funciona como explicação para um estilo de vida popular, apesar de seu conforto financeiro.

A narrativa do futebol como lugar do popular tem, no imaginário midiático compartilhado, um fundo musical: o pagode. Com frequência, o pagode é divulgado 
na mídia esportiva como uma das atividades preferidas de lazer dos jogadores de futebol. ${ }^{7}$ Na trilha sonora do Divino, o pagode fala sobre o bairro funcionando como metonímia de toda a periferia. É sintomática, nesse sentido, a utilização do samba Meu lugar (Arlindo Cruz / Mauro Diniz) para definir o bairro:

O meu lugar é caminho de Ogum com lansã,

Lá tem samba até de manhã, uma ginga em cada andar

O meu lugar é cercado de luta e suor

Esperança num mundo melhor e cerveja pra comemorar

O meu lugar tem seus mitos e seres de luz

É bem perto de Osvaldo Cruz, Cascadura, Vaz Lobo e Irajá

O meu lugar é sorriso, é paz e prazer

O seu nome é doce dizer:

É Divino!

A música foi lançada originalmente por Arlindo Cruz, em 2007, em homenagem ao bairro de Madureira e regravada para a trilha da novela com a substituição do nome do bairro por "Divino". O samba lento, acompanhado pelo banjo característico do pagode, da década de 1980 (que projetou Arlindo Cruz e seu ex-grupo Fundo de Quintal), e o estilo vocal "malandro" de Arlindo estabelecem um referente sonoro e afetivo bastante concreto para o bairro. É o Divino fictício inspirado na Madureira real, com um forte comércio de rua, um botequim de esquina que se abre para convívios comunitários e ainda por cima, um time de futebol de segunda divisão. ${ }^{8}$

Mas a música "popular" do Divino não se encerra nos domínios do samba e do pagode. Uma intensa atmosfera pop jovem atravessa toda a trilha sonora de Avenida Brasil. Nas trinta músicas que integram os dois CDs nacionais lançados, há artistas identificados com o funk, o sertanejo, a música romântica tradicional, o forró eletrônico e a MPB, além, evidentemente, do pagode. Um exemplo desse imaginário pop periférico é a canção $E u$ quero tchu, eu quero tcha (Shylton Fernandes), interpretada pela desconhecida dupla sertaneja João Lucas e Marcelo.

Cheguei na balada doidinho pra biritar

A galera ta no clima todo mundo quer dançar

7 A relação entre jogadores de futebol e o universo do samba e do pagode não é nova. Em 1982, o jogador da seleção brasileira Júnior chegou a lançar um compacto com o samba Voa Canarinho, voa, de sua autoria, sucesso em várias rádios do país na época. Uma rápida busca no portal de notícias da Rede Globo, o G1, comprova a simbiose constante entre o lazer dos jogadores de futebol e o gênero musical. Apresento alguns títulos: "No ritmo do pagode, seleção se prepara para a Copa do Mundo" (31/05/2010); "Do pagode aos cantos de louvor, Léo Moura prega paz no Flamengo" (09/05/2012); "Novato, Ronaldinho é 'batizado' e cai no pagode com colegas atleticanos" (06/06/2012); "Samba, pagode e futebol: Wellington Silva conhece verdadeiro Salgadinho" (04/10/2012); "Após madrugada de pagode, Adriano chega cedo ao Ninho do Urubu" (18/09/2012); "Enquanto não volta à Rússia, Hulk bate ponto em shows de pagode" (07/01/2013).

8 Na verdade, o Madureira Esporte Clube não é um time de segunda divisão. Encontra-se na primeira divisão do campeonato de futebol estadual e na terceira divisão (série C) do campeonato nacional. 
Uma mina me chamou, disse: "faz o tchu tcha tcha"

Perguntei "o que é isso?", ela disse: "eu vou te ensinar"

Eu quero tchu, eu quero tcha

Eu quero tchu tcha tcha tcha, tchu tcha tcha tcha

Na letra, a ambiência da "balada" é o cenário de um convite para a dança do tchu tcha tcha, sonoridade vocálica historicamente associada ao erotismo e ao sexo. ${ }^{9}$ A música está ambientada na sonoridade pop do sertanejo atual misturada criativamente com a batida do funk no refrão onomatopaico. O clipe de Eu quero tchu, eu quero tcha, foi lançado no Youtube em fevereiro de 2012 (antes da estreia de Avenida Brasil) e um ano depois conta com 16 milhões de acessos.

O sucesso da música tem relação direta com a comemoração do $100^{\circ}$. gol da carreira do craque do Santos Neymar, numa partida contra o Palmeiras em fevereiro de 2012. Ao "dançar" o tchu tcha tcha, Neymar ampliou a circulação da música, azeitando (ou abrindo as portas, não se sabe ao certo) sua inclusão na trilha da novela. O processo é semelhante ao ocorrido com Michel Teló no final de 2011, cuja dança de Ai se eu te pego (Antonio Diggs/Sharon Acioly) ganhou projeção internacional ao ser performativizada na comemoração de um gol do astro Cristiano Ronaldo, do Real Madrid.

Mais uma vez nesses dois casos, as conexões entre música e futebol se estreitam midiaticamente, ${ }^{10}$ permitindo divulgação em larga escala de estéticas e estilos de vida ligados a uma negociação do popular que não está inferiorizado economicamente, que se apresenta na grande mídia como detentor de uma voz ativa e que reivindica com ênfase e bom humor, espaço e respeito na sociedade. Nos gramados, nas telas e nos palcos, os enfrentamentos sociais e estéticos começam a ter mais espaço.

\section{Periferias musicais}

A ideia de periferia, articulada pelo repertório musical do Divino e do Borralho, precisa ser discutida de forma mais detalhada. Trata-se de um termo que vem ganhando notoriedade das últimas décadas tanto no âmbito dos debates conceituais acadêmicos quanto nas esferas midiáticas, em discursos políticos e em práticas culturais. Ocorre que o termo é vago o suficiente para ser encaixado em diversas situações, nem sempre com sentidos convergentes.

A palavra periferia refere-se, inicialmente, a uma dimensão geográfica, que é a matriz conceitual do termo. É periférico tudo aquilo que está em oposição ao central,

9 O exemplo mais evidente é o "tchan" do Grupo Gerasamba ("segura o tchan"), que, em 1995, protagonizou sucesso assombroso fortemente baseado no swing dançante do samba de roda pop baiano e na sensualidade erótica de suas dançarinas Débora Brasil e Carla Perez.

10 Em maio de 2012, João Lucas e Marcelo gravaram um videoclipe "oficial" da canção, com participação especial de Neymar e temática inteiramente voltada para os gramados. 
especialmente no que diz respeito a espaços de moradia e circulação física: bairros, cidades, países. Nessa oposição, reside um julgamento de valor relativo que decresce à medida que se afasta do centro. Bairros (ou países) periféricos são lugares alijados de benefícios, de facilidades, de conforto, de bem-estar social. São ainda indicadores de uma (má) qualidade de vida, desvalorizados em relação ao centro. Mas nem sempre essa distinção é tão simples. Se o Borralho pode ser facilmente identificado com o periférico, a caracterização do bairro Divino mascara essa dicotomia, estabelecendo algumas confusões.

A dualidade margens-centro sempre foi um dos principais componentes da identidade periférica e a quebra (ou mesmo apenas a aparente quebra) desta dualidade coincide com a emergência do questionamento deste tipo de dicotomia pela cultura, arte e teoria dos países ditos subdesenvolvidos. (PRYSTHON, 2003, p. 48)

O questionamento da centralidade é um artifício para neutralizar uma estrutura de poder que inferioriza e estigmatiza o periférico. É evidente que temos que ter em mente que a dualidade centro-periferia assume formas variadas e se manifesta de modo distinto nos vários espaços geográficos na qual ela é acionada. No contexto da circulação musical, a ideia de periferia cumpre a função de inverter o juízo de valor negativo que a dualidade aplica. Está em jogo aí uma ação política de positivação de um espaço desvalorizado, habitado por pessoas igualmente desvalorizadas nas hierarquias sociais.

Assim, a produção cultural do Borralho (como metonímia de toda periferia) provoca um deslocamento simbólico nessa hierarquia ao ultrapassar os seus limites físicos e obter reconhecimento nacional e internacional. ${ }^{11}$ Através dela, processa-se uma valorização das pessoas que habitam a periferia, cujos gostos, hábitos, práticas cotidianas, gírias, roupas e músicas amplificam-se, produzindo embates que se deslocam de uma matriz de denúncia para uma apologia festiva, quase sempre protagonizada pela produção cultural.

Contudo, todo esse processo tende a negligenciar a diversidade de ideias que atravessam os modos de ser popular e periférico. Hall identifica duas definições para a noção de "cultura popular": (1) "algo é 'popular' porque as massas o escutam, compram leem, consomem e parecem apreciá-lo imensamente" (HALL, 2003, p. 253) e (2) "a cultura popular é todas as coisas que o 'povo' faz ou fez" ibid., p. 256). Ambas as definições são consideradas insatisfatórias para o autor, pois tendem a universalizar as práticas culturais populares, ignorando suas contradições e ambiguidades (ibid., p. 257). Sob a rubrica do popular estão inscritas manifestações e criações artísticas extremamente variadas e muitas vezes conflitantes, que se unem a partir de uma percepção de inferioridade num contexto de assimetrias de poder.

11 Na novela, além do sucesso musical das Empreguetes, formulado, produzido e formatado no Borralho, o grafiteiro Rodinei (Jayme Matarazzo) alavanca a partir dos muros da favela uma bem sucedida carreira internacional no elitista mercado de arte, intermediado por uma curadora sensível e apaixonada. 
De fato, as músicas que integram as trilhas sonoras das novelas (para nos retermos aos casos estudados) apresentam sonoridades e origens altamente diversificadas, abordando uma ampla "pluralidade de modos de existência do popular" (MARTíN-BARBERO, 2001, p. 321). Por outro lado, o uso do termo periferia para referir-se a todo esse conjunto variado de músicas funciona como componente aglutinador que não estabelece uma uniformidade nem apaga as contradições, mas que funciona como vetor de uma ação estética comum. O que todas essas músicas estão apontando é para a necessidade de negociar uma posição para o popular periférico que não estigmatize seus gostos e sua posição social.

\section{Oi oi oi: créditos finais}

Nessa seção final, gostaria de direcionar nossa escuta para a abertura de Avenida Brasil, que trazia uma ambientação de festa noturna, "onde dezenas de pessoas vistas em silhuetas dançam animadas, iluminadas por luzes cujas cores vêm dos faróis e luminosos que fazem o fundo de quadro desfocado" (RAHDE et. al, 2012, p. 334). Em artigo sobre a novela, Rahde e colaboradores identificam uma inspiração direta dos faróis luminosos com a estética visual do cinejornal Canal 100, especializado em futebol e exibido entre 1959 e 1986, reforçando a temática futebolística como narrativa da novela e do universo popular (ibid.) ${ }^{12}$.

A música de abertura de Avenida Brasil tem um histórico transnacional. Vem dançar kuduro foi lançada originalmente no Youtube, em 2010, por seu compositor luso-francês Lucenzo, com participação especial do rapper nova-iorquinho Big Ali. Com 18 milhões de acessos em cinco meses, a música alcançou sucesso na Europa e no Canadá. Em agosto do mesmo ano, o cantor de reggaeton porto-riquenho, Don Omar, relança a música com o título Danza kuduro, com participação de Lucenzo (e um novo clipe no Youtube) e acomoda a canção entre os vídeos mais acessados do site. ${ }^{13}$ No Brasil, o cantor Latino lança a música, em 2011, e, após um processo judicial por utilização indevida, a música aparece na abertura da novela interpretada por Lino Krizz e Robson Moura.

O movimento internacional da canção é interessante para a reflexão sobre periferia. O kuduro é um gênero musical de Angola, que resulta do cruzamento de ritmos locais (sungura, kizomba e semba) com o eletrônico do rap e do hip hop. Sendo uma dança altamente erótica e ligada a festas urbanas jovens, o gênero se internacionalizou através de artistas como M.I.A. A migração do gênero das periferias de Luanda para a mesa de criação de Lucenzo e de lá para a viralidade do Youtube e para a abertura de Avenida Brasil pode ser entendida como um processo de negociação de referências tensivas entre centro e periferia. O kuduro, o reggaeton, o hip hop e o funk são práticas musicais nascidas em lugares periféricos da hierarquia geográfica mundial, que se tornam cosmopolitas através do compartilhamento de uma sensação de periferia.

12 Mais informações sobre o programa no excelente site: <www.canal100.com.br>

13 Em 07/02/2013, a contagem estava em 423 milhões de acessos. 
Esse movimento é concomitante, no Brasil, com a ampliação do consumo da chamada "classe $C$ ", que aciona em nível nacional também um reposicionamento da periferia, feito igualmente através da música e da internet. Os processos de ampliação de falas e escutas periféricas convergem e atuam de modo complementar, alterando hierarquias e ocupando espaços na sociedade e nas mídias. A periferia das músicas periféricas de massa advoga um sentido positivo para o popular, distante do tom acusatório e grave de outras manifestações. E com grande sucesso.

Com isso, essas músicas engarrafam significados em avenidas congestionadas, tencionam vias interpretativas e incomodam os lugares estabelecidos. São músicas impertinentes, muitas vezes agressivas e invasivas. Impõem-se na paisagem urbana, vazando horários de silêncio e veiculando condutas morais discutíveis ou frontalmente ilegais, desrespeitando opiniões alheias e faixas etárias inapropriadas. Circulam pelas ruas em alto volume, frequentam espaços sociais diversos como penetras num clube. A música é uma plataforma do conflito social, mas também das negociações e de alguns consensos. Aguardemos os próximos capítulos!

Felipe da Costa Trotta é docente do Departamento de Estudos Culturais e Mídia e do PPG em Comunicação da UFF, doutor em Comunicação e Cultura (UFRJ, 2006) e mestre em Musicologia (UNIRIO, 2001). Pesquisador do CNPq e da Faperj, dedica-se à interface entre música popular e comunicação.

trotta.felipe@gmail.com

\section{Referências}

BARROS, Carla. Representações do serviço doméstico na ficção televisiva. Animus, Santa Maria, v. 11, n. 22, 2012.

BLACKING, John. Music, culture and experience. Chigaco: Chicago University Press, 1995.

CASTRO, Gisela. Cheias de charme: a classe trabalhadora no paraíso da cibercultura. Ciberlegenda, n. 27,2012

DAMO, Arlei. Do dom à profissão. Tese de doutorado em Antropologia Social. Porto Alegre, UFRGS, 2005.

FRANÇA, Vera; VAZ, Paulo B. "A felicidade na Avenida Brasil". In: M. HERSCHMAM, Micael; RIBEIRO, Ana Paula Goulart; FREIRE FILHO, João (orgs.). Entretenimento felicidade e memória. São Paulo: Anadarco, 2012.

HALL, Stuart. "Notas sobre a desconstrução do 'popular'". In: Da diáspora. Belo Horizonte: Editora UFMG, 2003. 
HELAL, Ronaldo. A construção das narrativas de idolatria no futebol brasileiro. Alceu, Rio de Janeiro, n.7, 2003.

IORIO, Patrícia. Avenida Brasil e o subúrbio carioca. In: INTERCOM, 35. Anais. Fortaleza: Intercom, 2012.

JUNQUEIRA, Lília. Desigualdades sociais em telenovelas. São Paulo: Annablume, 2009.

KANYAT, Lizbeth. Comunicação, consumo e cultura: as massas e os clássicos literários. Acta Científica, São Paulo, v. 21, n. 2, 2012.

LIMA, Cecília; MOREIRA, Diego. Operações no conceito de hipertelevisão na novela Cheias de charme. In: INTERCOM, 35. Anais. Fortaleza, Intercom, 2012.

MARTÍN-BARBERO, Jésus. Dos meios às mediações. Rio de Janeiro: Ed.UFRJ, 2001.

MAURO, Rosana; TRINDADE, Eneus. Telenovela e discurso como mudança social na análose da personagem Maria da Penha em Cheias de Charme. Em Questão, Porto Alegre, v. 18, n. 2, 2012.

NEGRI, Marcelo. A nova classe média: o lado brilhante dos pobres. Rio de Janeiro: FGV, 2010.

PRYSTHON, Ângela. Margens do mundo: a periferia nas teorias do contemporâneo. Famecos, Porto Alegre, n. 21, 2003.

RAHDE, M. Beatriz F.; TIETZMANN, Roberto; COSTA, Cristiane; DORFMAN, Beatriz. Avenida Brasil: o popular com pós-modernismo televisivo. Estudos em Comunicação, Covilhã, n.12, 2012.

RONSINI, Veneza. A crença no mérito e a desigualdade. Porto Alegre: Sulina, 2012.

SIFUENTES, Lírian; VILELA, Mateus; JEFFMAN, Tauana. O dia em que a internet congelou. Sessões do Imaginário, Porto Alegre, n. 27, 2012.

TARAPANOFF, Fabíola; FERNANDES, Julio Cesar. Reflexo de uma ascensão: o imaginário da "classe $C^{\prime \prime}$ nas novelas "Cheias de charme" e "Avenida Brasil". In: INTERCOM, 35. Anais. Fortaleza, Intercom, 2012.

Artigo recebido em abril e aprovado em junho de 2013. 